\title{
Coalizão advocatória e aprendizado nas políticas públicas: as mudanças nas convicções centrais do PAIC
}

\author{
Lilia Asuca Sumiya ${ }^{1}$ \\ ORCID: 0000-0002-6938-8731 \\ Hironobu Sano ${ }^{1}$ \\ ORCID: 0000-0002-4955-8895
}

\section{Resumo}

O objetivo deste artigo é compreender o processo de formação de uma coalizão que levou o Programa de Alfabetização na Idade Certa (PAIC) do Ceará a se tornar uma política prioritária no estado. Foi adotado o modelo das coalizões advocatórias (ACF) para analisar o papel dos principais atores no desenvolvimento da coalizão, caracterizar seu sistema de crenças e o processo de aprendizagem na política. A pesquisa envolveu o levantamento de documentos institucionais do programa, teses e dissertações, notas taquigráficas de audiências públicas, matérias na mídia e entrevistas com os principais envolvidos. A análise da trajetória das principais ideias ao longo de dez anos, que se iniciou com a experiência dos gestores em Sobral, Ceará, em 1997, e culminou com sua chegada ao governo do estado, em 2007, permitiu caracterizar a composição de uma única coalização. A formação e a disseminação do conjunto de crenças ocorreram a partir da atuação do Comitê Cearense para a Eliminação do Analfabetismo Escolar (CCEAE), formando uma forte coalizão com participação de diversos especialistas e instituições, bem como de atores municipais. Foram identificadas três camadas de crenças e, com relação às convicções centrais da política pública, foram caracterizados sete componentes, divididos em dois períodos de análise. A mudança nas convicções centrais foi analisada a partir da perspectiva da aprendizagem nas políticas públicas, considerando o processo de reflexão dos principais atores.

\section{Palavras-chave}

Coalizão advocatória - Sistema de crenças - Aprendizagem nas políticas públicas Políticas públicas em educação - PAIC.

1- Universidade Federal do Rio Grande do Norte, Natal, RN, Brasil. Contatos: lilia.sumiya@ufrn.br; hironobu.sano@ufrn.br 


\section{Advocacy coalition and learning from public policies: changes in PAIC's core convictions}

\section{Abstract}

The objective of this article is to understand how a coalition was formed that led he Literacy at the Right Age Program (PAIC) in Ceará to become a priority policy in the state. The Advocacy Coalition Framework (ACF) was adopted to analyze the role of the key actors in the coalition's development, characterize its belief system and the learning process in policy. The research was based on a survey of institutional documents of the program, theses and dissertations, shorthand notes of public hearings, media news and interviews with key stakeholders. The analysis of the trajectory of the main ideas over ten years, which began with the experience of public managers in Sobral, Ceará, in 1997, and culminated with they taking over the state government in 2007, allowed us to characterize the composition of a single coalition. The formation and dissemination of the beliefs stemmed from the performance of the Ceara's Committee for the Elimination of School Illiteracy (CCEAE), which established a strong coalition with the participation of several specialists and institutions, as well as municipal actors. Three layers of beliefs were identified and, in relation to the core convictions of public policy, seven components were characterized, divided into two periods of analysis. The change in core convictions was analyzed from the perspective of policy learning, considering how the main actors reflected about it.

\section{Keywords}

Advocacy Coalition - Belief System - Learning from Public Policies - Educational Public Policies - PAIC.

\section{Introdução}

Este artigo tem como objetivo compreender a formação da coalizão advocatória, bem como a atuação dos atores, que levou o Programa de Alfabetização na Idade Certa (PAIC) ao topo da agenda governamental cearense em 2007. Com essa política, a rede pública de educação do Ceará apresentou a melhor evolução nacional no Índice de Desenvolvimento da Educação Básica (IDEB) dos anos iniciais do ensino fundamental, passando de 2,8 em 2005, para 6,1 em 2017, um aumento de 118 por cento, fazendo do Ceará um dos estados com os melhores desempenhos.

Esse resultado foi alcançado mesmo em municípios que apresentam baixos indicadores sociais. Em 2018, 42,8 por cento dos cearenses viviam abaixo da linha da pobreza, sendo mais significativo no interior do que na capital, o que torna o Ceará o oitavo estado do Brasil com o maior índice de pobreza e de extrema pobreza (IBGE, 2019). Contrariando os estudos que relacionam os fatores extraescolares ao baixo desempenho 
educacional, o caso do Ceará atrai interesse acadêmico, uma vez que, mesmo em condições adversas, os fatores intraescolares têm se mostrado fundamentais para o desempenho (ALVES; SOARES, 2013).

De fato, o PAIC tem sido analisado a partir de diferentes olhares, com estudos que abordam questões pedagógicas e formação de professores (FONSECA, 2013); coordenação estadual e implementação (SEGATTO, 2017; BONAMINO et al. 2019); eficácia da política (COSTA; CARNOY, 2015) e, mais recentemente, sobre equidade (KASMIRSKI; GUSMÃO; RIBEIRO, 2017) e governança (MAIA, 2020; VIEIRA; PLANK; VIDAL, 2019). Cabe lembrar também que o PAIC do Ceará inspirou a criação do Programa Nacional pela Alfabetização na Idade Certa (PNAIC), programa do MEC lançado nacionalmente em 2012 e finalizado em 2017, sobre o qual já foram identificados 64 estudos (ALFERES; MAINARDES, 2019). Apesar de o PAIC atrair interesse de uma variedade de olhares acadêmicos, ainda não há um estudo da iniciativa a partir das coalizões, sobretudo considerando as crenças e valores defendidos pelos atores, bem como suas mudanças ao longo do tempo. Os estudos de políticas públicas a partir dessa lente analítica já são adotados no Brasil em diferentes áreas, tais como na política de combate às drogas, ambiental, energética, esportiva, entre outros (CAPELARI; ARAÚJO; CALMON, 2015; BUENO, 2008). Na educação, os principais trabalhos foram encontrados em Simielli (2013), que identificou a coalizão de dois grupos que lutam pela melhoria da qualidade da educação no Brasil, e em Rocha (2011), que discute o papel das ideias, atores e formação de agenda na reforma educacional de Minas Gerais. Tal qual este estudo, os dois trabalhos não identificaram coalizões opostas, mas diferentes atores e instituições que compartilham do valor e importância da educação.

Considerando o contexto e o objetivo apresentados, este artigo tem como objetivos específicos: a) analisar o papel dos principais atores no desenvolvimento da coalizão; b) caracterizar o sistema de crenças na coalizão; e c) analisar o processo de aprendizagem na política.

A análise demanda uma busca pelas origens das ideias centrais presentes no PAIC, o que leva ao município de Sobral, no interior do estado, onde as primeiras ideias foram implementadas em 1997. A trajetória que levou à formação de uma ampla coalizão estadual em torno do PAIC, que culminou em 2007 com a criação do programa em âmbito estadual, torna o caso propício para ser analisado sob a lente teórica das coalizões.

0 período de dez anos também possibilita uma análise a partir do conceito de aprendizagem nas políticas públicas, que considera o processo de reflexão e reação dos atores frente aos resultados alcançados pelas políticas públicas, levando-os a reforçar ou refutar as relações causais presentes nas suas convicções (HALL, 1993; SABATIER; WEIBLE, 2007).

Este artigo conta, além desta introdução, com outras quatro partes. Na segunda seção, apresenta-se o referencial teórico das coalizões advocatórias, com destaque para o sistema de crenças e a aprendizagem nas políticas públicas; na terceira seção, apresentase a metodologia; na quarta seção, passa-se a discussão do caso, dividido em três fases, seguida de análise sobre as crenças e o aprendizado nas políticas públicas. Por fim, são realizadas as considerações finais. 


\section{O modelo de coalizão advocatória}

Os primeiros estudos sobre coalizões remontam à década de 1950, quando foram publicados estudos seminais da área de psicologia sobre o comportamento de indivíduos em pequenos grupos que interagiam (CAPLOW, 1956; VINACKE; ARCKOFF, 1957). Nos anos posteriores, diversos experimentos foram realizados com o intuito de testar hipóteses sobre a formação de uma coalização (CHERTKOFF, 1966; GAMSON, 1961). Esses estudos buscavam, inclusive, diferenciá-los da abordagem racional baseada nas premissas econômicas, tendo identificado outros fatores capazes de afetar o comportamento dos atores. Ao longo das décadas de 1960 e 1970, foram desenvolvidos os modelos teóricos básicos de formação de coalizões governamentais, temática que ganhou mais impulso ao final de 1980 (DÖRING; HELLSTRÖM, 2013).

Em 1988, Sabatier apresentou o modelo analítico de Coalizão Advocatória Advocacy Coalition Framework (ACF) - que tem como proposta explicar as mudanças nas políticas públicas a partir da atuação de coalizões, cada qual defendendo suas próprias convicções. A análise é realizada a partir da delimitação de uma política pública específıca e da identificação dos diferentes atores que estão ativamente envolvidos na temática. A ACF identifica que as crenças são o fator causal do comportamento político e envolve "valores prioritários, percepções acerca de importantes relações causais, percepções sobre a situação do mundo e sobre a eficácia dos instrumentos de políticas públicas" (SABATIER, 1988, p. 132, tradução nossa). A atuação das pessoas na política é justificada, ao menos em parte, para traduzir suas crenças em políticas públicas.

0 sistema de crenças pode ser compreendido a partir de uma estrutura em três camadas, conforme a Figura 1. Quanto mais próximo do centro, mais difícil é provocar uma alteração nas convicções.

Figura 1 - 0 sistema de crenças e suas camadas

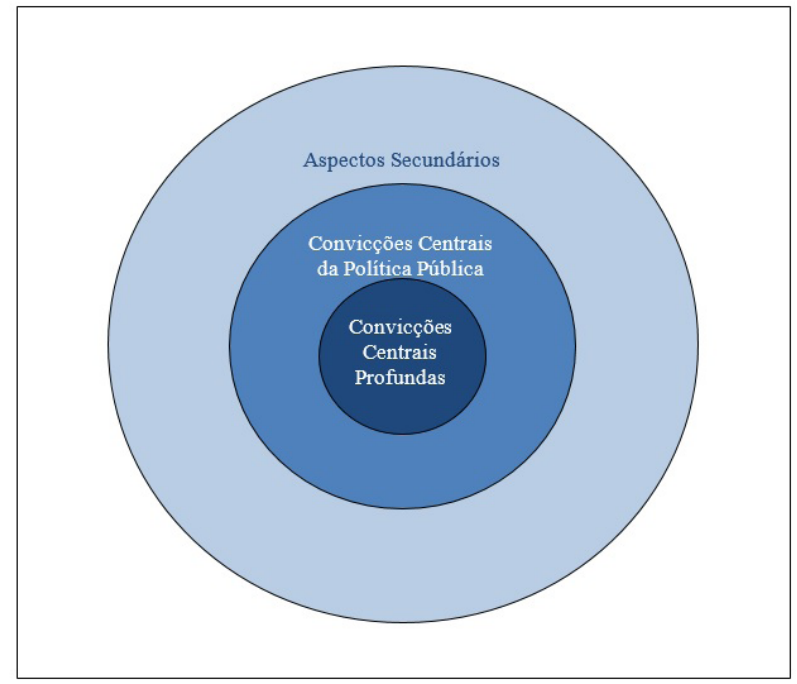

Fonte: Adaptado de Bueno (2008). 
A parte interna do sistema de crenças - as convicções centrais profundas - é composta pelos valores a partir dos quais o indivíduo irá interpretar o mundo, ou seja, apresentam um caráter normativo e são muito difíceis de mudar. Na camada intermediária estão as crenças e valores que emanam das convicções centrais profundas e que, ao mesmo tempo, buscam concretizá-las. São as convicções centrais das políticas públicas que incluem as estratégias básicas e as convicções acerca das relações causais de uma política pública.

É a partir do compartilhamento dessa segunda camada que ocorre a formação das coalizões, proporcionando, ainda, a coordenação das atividades entre os membros. Sabatier e Jenkin-Smith (1993) apresentam dez componentes das convicções centrais das políticas públicas, subdivididos em preceitos normativos fundamentais e preceitos empíricos. Uma discordância nesses componentes pode levar a uma subdivisão na coalizão ou à criação de uma nova coalizão.

Por fim, a camada mais externa é composta pelos aspectos secundários que correspondem a elementos administrativos, operacionais e informações que apoiam as decisões instrumentais sobre a implementação de uma política pública. Os autores sustentam que é a camada mais sujeita a mudanças ao longo do tempo, seja por tensões dentro de uma coalização ou por influência de coalizões concorrentes.

Sabatier e Weible (2007) identificaram algumas situações que podem provocar mudanças nos valores centrais das políticas públicas: perturbações externas ou internas, acordos entre as coalizões e o aprendizado nas políticas públicas. Essa última é resultado da experiência e de novas informações que indicam o sucesso ou a fragilidade das políticas públicas adotadas e levam, portanto, a um reforço ou revisão das crenças e valores da camada intermediária.

Os autores do ACF também destacam três importantes aspectos do processo de aprendizagem: monitoramento das metas das políticas implementadas e que possam revelar falhas no desempenho; reflexões que os atores realizam a respeito das relações causais do sistema de crenças, ou seja, envolve uma análise sobre as razões que levaram ou não aos resultados almejados; e, por fim, o processo de identificar e responder aos desafios que se apresentam a um sistema de crenças, e que podem se referir tanto a fatores externos como internos. Em suma, o aprendizado nas políticas públicas "envolve a ampliação do conhecimento acerca dos parâmetros do problema e dos fatores que os afetam, e mudanças na percepção dos impactos prováveis de políticas públicas alternativas" (SABATIER; JENKINSSMITH, 1993, p. 43), abordagem que se baseia em Hall (1993) e Hall e Taylor (2003).

\section{Percurso metodológico}

0 trabalho tem natureza qualitativa e adota como estratégia o estudo de caso explanatório, caracterizada como caso crítico, pois tem como proposta apresentar elementos que permitam testar uma teoria (YIN, 2005).

A busca das fontes de documentação relativa às origens do PAIC foi realizada no site institucional da Secretaria de Educação do Ceará e do programa, bem como a partir de artigos, teses e dissertações na base de dados da Coordenação de Aperfeiçoamento de Pessoal de Nivel Superior (CAPES) e na biblioteca da Universidade Federal do Ceará (UFC). No centro de documentação da Assembleia Legislativa do Ceará (ALECE) foi possível 
encontrar todas as legislações referentes ao PAIC, os pronunciamentos dos deputados sobre o tema e os documentos do Comitê Cearense para a Eliminação do Analfabetismo Escolar (CCEAE). 0 acesso às notas taquigráficas dos eventos realizados há mais de uma década (sete audiências públicas na capital e nas cidades-polo do interior, seis plenárias gerais do comitê e dois seminários), que totalizaram 823 páginas, se revelaram imprescindíveis para a compreensão de como a coalizão foi sendo construída a partir da disseminação dos valores centrais dos atores-chave, que será apresentado e analisado na próxima seção.

A pesquisa foi complementada com outros documentos institucionais, artigos e notícias veiculadas na mídia local e nacional. Após a identificação dos principais participantes, na segunda etapa, ocorreu a pesquisa de campo com a realização de dezesseis entrevistas semiestruturadas com atuais e ex-membros do governo cearense, acadêmicos e representantes de instituições parceiras. Dessa forma, visou-se à triangulação de métodos (DENZIN; LINCOLN, 2006). As entrevistas ocorreram entre agosto de 2014 e abril de 2015, com o consentimento de todos os participantes na sua divulgação.

A transcrição de entrevistas, de notas taquigráficas e os documentos institucionais foram objetos de análise de conteúdo, organizados a partir das categorias de análise extraídas de Sabatier e Jenkins-Smith (1993), quais sejam: i) convicções centrais profundas, ii) convicções centrais da política pública (subdivididas em preceitos normativos e empíricos, conforme o Quadro 3) e iii) aspectos secundários da política pública. 0 método de análise qualitativo para estudos de caso seguiu os estudos de Kohlbacher (2006) e Mayring (2000). A análise desses elementos possibilitou compreender a trajetória histórica de formação da coalizão e o processo de aprendizagem nas políticas públicas que levou à consolidação das crenças e valores centrais, e que, ao fim, tornou o PAIC uma política estratégica do governo estadual.

\section{Análise}

A discussão do caso está dividida em três fases: inicia-se com a apresentação da experiência vivenciada no governo local de Sobral, município distante 231 quilômetros da capital Fortaleza; a segunda fase é a etapa da mobilização e disseminação dos valores; e, por último, ocorre a fase de consolidação desses valores e que levou à formulação do PAIC. A trajetória histórica apresentada permite, por fim, discutir como se deu a formação de crenças e valores, associada ao processo de aprendizado na política educacional cearense.

\section{Primeira fase: Sobral e a mudança nas convicções centrais da política educacional}

A primeira fase corresponde ao período no qual ocorreu uma mudança nas convicções centrais da política educacional em função dos resultados alcançados na área.

0 primeiro aspecto a se ressaltar é o foco representado pela eleição municipal de 1996, vencida por Cid Gomes, que representava até então um grupo político de oposição. Durante sua primeira gestão, de 1997 a 2000, a educação no município passou por várias mudanças, inserindo-se no cenário de importantes marcos na área educacional do país, como a aprovação da nova Lei de Diretrizes e Bases da Educação Nacional (LDB/1996) 
e, principalmente, pelo impacto do Fundo de Manutenção e Desenvolvimento do Ensino Fundamental e Valorização do Magistério, o FUNDEF, de 1996.

Com a implementação do FUNDEF, Sobral, como muitos municípios brasileiros, conseguiu promover melhorias no salário dos professores, realizou concursos públicos e investiu na reforma e construção de escolas. Até então, as escolas municipais, especialmente as rurais, eram vítimas do patrimonialismo e clientelismo e apresentavam péssimas condições de infraestrutura, sendo chamadas de merendório (BECSKEHÁZY, 2018). Como resultado do investimento, a rede municipal de Sobral passou de 9.000 para aproximadamente 20.000 alunos, mais do que dobrando a sua capacidade de atendimento no ensino fundamental. Se incluirmos toda a educação básica municipal, houve um aumento de 157 por cento nas matrículas, que passou de 12.631 para 32.566 alunos (MAIA, 2006).

A análise desse período permite identificar as principais características definidoras do sistema de crenças: a principal convicção central profunda é baseada na perspectiva dos direitos e se reflete na busca pela universalização do acesso e que, por seu turno, se concretiza por meio de políticas públicas voltadas à construção e reforma de escolas, somada à municipalização. Esses investimentos tinham como objetivo melhorar a qualidade da educação (BECSKEHÁZY, 2018). Observa-se, portanto, que a relação causal estabelecida nesse sistema de crenças é a de que investimentos em infraestrutura e aumento na remuneração do professor levariam a uma melhoria na qualidade da educação.

A surpresa veio ao final da gestão, em 2000, quando o município aplicou uma avaliação própria e o resultado apontou que 48 por cento das crianças que estavam terminando o segundo ano não sabiam ler (INEP, 2005). Sobral ainda recebeu, no mesmo ano, o resultado de uma avaliação externa de aprendizagem de alunos de primeira e quarta séries, ficando em penúltimo lugar entre os 52 municípios brasileiros participantes do exame ${ }^{2}$ (INEP, 2005). Diante desses resultados, o então secretário de educação, Ivo Gomes, afirmou:

[...] e quando chegou o resultado, para nós foi uma coisa estarrecedora: decepção total, tristeza geral, perplexidade, angústia... e isso fez com que acendesse uma luz vermelha na prefeitura. Porque a gente tinha a sensação de que tudo que tinha que ser feito estava sendo feito [...]. (informação verbal) ${ }^{3}$.

A percepção de que os resultados não foram os esperados corresponde à primeira etapa do processo de aprendizagem nas políticas públicas, o que leva a uma reflexão sobre as relações causais previamente assumidas em seu sistema de crenças. Reformulações, entretanto, somente seriam possíveis num segundo mandato. Embora o baixo desempenho na educação não tenha sido um fator impeditivo para a reeleição do prefeito, documentos históricos mostram o comprometimento da liderança política para mudar essa realidade. Um dos exemplos ilustrativos da indignação perante o problema detectado no seu município encontra-se no pronunciamento de Cid Gomes, em janeiro de 2001, na ocasião de sua posse para o segundo mandato na Prefeitura de Sobral:

2- Nessa época, o município participava do Programa Acelera Brasil, do Instituto Ayrton Senna, que realizou a avaliação elaborada pela Fundação Carlos Chagas com todos os municípios parceiros.

3- Entrevista concedida por Ivo Gomes ao Instituto Alfa e Beto (SOBRAL..., 2013). 
A gente ainda encontra, hoje, alunos matriculados na quarta série do Ensino Fundamental, pasmem, analfabetos, na rede municipal. Encontram-se hoje, matriculados na quarta série, e eu não posso sair, e nem jogar a responsabilidade para outros gestores ou para outros administradores do setor, isso é responsabilidade ou deficiência da nossa, da minha administração. (informação verbal) ${ }^{4}$.

No início do segundo mandato (2001-2004) foi realizado um novo diagnóstico, que identificou um baixo desempenho dos alunos de segunda à quarta série. Os indicadores deixaram claro para a equipe municipal que não adiantaria continuar envidando esforços apenas na infraestrutura e remuneração e novos objetivos foram estabelecidos. Nesse processo de reforma, diferentes atores e instituições colaboraram nas mudanças empreendidas, com destaque para o professor Edgard Linhares, especialista em leitura da UFC, que desenvolveu o primeiro sistema de avaliação no município, e João Batista Oliveira, então consultor do Instituto Ayrton Senna, que atuava no município no âmbito do Programa Escola Campeã, voltado para o fortalecimento da capacidade gerencial das secretarias e das escolas (SUMIYA, 2015).

Com o apoio desses atores, a equipe técnica municipal estabeleceu como meta prioritária a alfabetização de 100 por cento das crianças em processo inicial de escolarização até os 7 anos de idade, seguida pela alfabetização de 100 por cento das crianças de 8 anos ou mais, que frequentavam da segunda à sexta série e que ainda não sabiam ler e escrever (MAIA, 2006). Essas metas refletiram as novas convicções centrais da política pública.

Para o atingimento das metas, várias estratégias foram delineadas, derivadas do novo sistema de crenças, como destacadas no Quadro 1.

Quadro 1 - Estratégias da política educacional de Sobral (2001-2004)

\begin{tabular}{|c|l|}
\hline \multicolumn{1}{|c|}{ Área } & \multicolumn{1}{c|}{ Ações } \\
\hline Organizacional & $\begin{array}{l}\text { - } \text { diminuição das unidades multisseriadas na área rural. } \\
\text { - ampliação do ensino fundamental de nove anos, incluindo crianças de } 6 \text { anos, antes mesmo da promulgação da lei } \\
\text { nacional que estabeleceu essa obrigatoriedade. } \\
\text { - municipalização dos anos iniciais do ensino fundamental, em cooperação com o estado, o que permitiu foco na } \\
\text { aprendizagem das crianças. }\end{array}$ \\
\hline Gestão administrativa & $\begin{array}{l}\text { - seleção dos gestores escolares por meio de critérios técnicos. } \\
\text { - formação continuada e capacitação dos gestores escolares. } \\
\text { - garantia de autonomia financeira, pedagógica e administrativa para as escolas. } \\
\text { - monitoramento dos dados relativos às ações da escola. } \\
\text { - gratificação para o professor alfabetizador, atraindo os melhores professores para esse nível de ensino, antes preterido } \\
\text { por requerer maior esforço. } \\
\text { - implementação de um sistema de avaliação. } \\
\text { - criação do Prêmio Escola Alfabetizadora para mobilizar os esforços das escolas nas conquistas das metas de } \\
\text { alfabetização. }\end{array}$ \\
\hline Pedagógica & $\begin{array}{l}\text { - produção de material de alfabetização próprio com estruturação da rotina da sala de aula. } \\
\text { - formação de professores atrelada à prática na sala de aula, com estabelecimento de rotinas. }\end{array}$ \\
\hline
\end{tabular}

Fonte: Elaboração própria, a partir de INEP (2005).

4- Entrevista concedida por Cid Gomes, em 2001, disponível no sexto vídeo institucional 2014 do PAIC (SEXTO..., 2015) 
Em 2004, apenas três anos após o início da reforma, o município já apresentava um percentual de 95,7 por cento dos alunos de primeiro ano considerados leitores (INEP, 2005). Esse indicador serviu para fortalecer as convicções centrais da política pública ao reforçar a relação causal entre as mudanças empreendidas e os resultados alcançados. Nesse processo, segundo os gestores, estabelecer a meta de idade de 7 anos como limite para que ocorra a alfabetização mostrou-se, não só adequada, como importante ao direito do aluno aprender (MAIA, 2006).

Os bons resultados também indicam um novo processo de aprendizagem nas políticas públicas. Observa-se, portanto, que a melhoria da educação vai além dos aspectos pedagógicos e incorpora a dimensão da gestão pública, sendo abordadas de forma conjunta. Esse aprendizado é levado pelo principal empreendedor de política pública ${ }^{5}$, o então secretário municipal de educação Ivo Gomes, para a esfera estadual, quando foi eleito deputado para o mandato de 2003 a 2006, processo analisado em detalhes em Sumiya, Araujo e Sano (2017).

\section{Segunda fase: Mobilização e formação de coalizão no estado do Ceará}

Eleito com a bandeira de atuar na melhoria da educação, o desafio do novo deputado era convencer os demais municípios cearenses de que eles também enfrentavam o mesmo problema constatado em Sobral, ou seja, o analfabetismo escolar. A divulgação dos dados do Sistema de Avaliação da Educação Básica (SAEB) 2001, que confirmavam que mais de 70 por cento das crianças do ensino fundamental (quarta série) apresentavam dificuldades graves de leitura no estado, contribuiu para a sensibilização.

Com os dados em mãos, o deputado Ivo Gomes procurou o apoio do Fundo das Nações Unidas para a Infância (UNICEF) e do então presidente da Assembleia Legislativa do Ceará (ALECE). A proposta inicial era a criação de uma Comissão Parlamentar de Inquérito, mas as discussões levaram à formação de um comitê que realizasse um diagnóstico sobre o problema da educação no estado: o Comitê Cearense pela Eliminação do Analfabetismo Escolar (CCEAE).

O CCEAE foi definido como instância de caráter plural, democrática e representativa, um pacto societário para a superação do analfabetismo escolar, firmado entre várias forças da sociedade cearense (CCEAE, 2006). 0 termo eliminação do analfabetismo escolar foi a primeira divergência no âmbito do CCEAE e levantado pelos acadêmicos, que questionaram o uso de uma linguagem bélica e que não indicava um quadro positivo para a promoção da alfabetização. Contudo, apesar das críticas, os organizadores mantiveram o nome, pois expressava de forma clara e objetiva o problema a ser enfrentado.

0 que se observou em seguida foi o início da formação de uma coalizão, pois várias entidades passaram a se juntar à iniciativa: a Secretaria da Educação do Ceará (SEDUC), a União dos Dirigentes Municipais de Educação (UNDIME-CE) e o Instituto Nacional de Estudos e Pesquisas Educacionais Anísio Teixeira (INEP) foram os participantes pioneiros

5- De acordo com a definição de Kingdon (1995, p. 179), empreendedores de políticas públicas são pessoas "dispostas a investir seus recursos para promover uma ideia em troca de ganhos futuros na forma de benefício material, específico ou coletivo". 
na elaboração do projeto. Ao longo do processo, juntaram-se ao comitê cinco universidades cearenses, três associações representativas de gestores municipais, cinco associações que atuam na defesa da educação e/ou de seus profissionais, bem como quatro instituições que apoiaram a iniciativa financeiramente (CCEAE, 2006). Tratava-se, portanto, da formação de um grupo alinhado com as ideias defendidas pelo deputado estadual e pelo comitê.

As ações empreendidas pelo comitê foram divididas em duas frentes, desenvolvidas ao longo do ano de 2004: a de investigação e de mobilização social. A primeira consistiu na realização de três pesquisas tendo como base a experiência de Sobral e atraiu o interesse de noventa municípios, indicando uma aceitação das ideias do CCEAE. Em razão das restrições orçamentárias, porém, foram selecionados 48 deles. Os resultados, resumidos no Quadro 2, comprovaram as suspeitas do comitê quanto à baixa qualidade da educação.

Quadro 2 - Frente de investigação: objetivos e resultados das pesquisas

\begin{tabular}{|c|c|}
\hline Objetivos & Principais resultados \\
\hline $\begin{array}{l}\text { Pesquisa I } \\
\text { Diagnosticar o nível de alfabetização } \\
\text { infantil em três dimensões: leitura, escrita e } \\
\text { compreensão de texto. }\end{array}$ & $\begin{array}{l}\text { - } 3 \% \text { das crianças avaliadas apresentaram o nível recomendado de alfabetização para a idade } \\
\text { - } 15 \% \text { das crianças leram e compreenderam o texto } \\
\text { - } 42 \% \text { das crianças produziram algum tipo de texto }\end{array}$ \\
\hline $\begin{array}{l}\text { Pesquisa II } \\
\text { Identificar a organização das secretarias, } \\
\text { escolas e dos professores para garantir a } \\
\text { alfabetização de crianças. }\end{array}$ & $\begin{array}{l}\text { - alfabetização não é prioridade nos municípios e nas escolas } \\
\text { - problemas no acompanhamento pedagógico } \\
\text { - não há organização do tempo e do espaço escolar para a alfabetização } \\
\text { - maioria dos professores não tem metodologia para alfabetizar } \\
\text { - muito tempo de aula utilizado para atividades não escolares }\end{array}$ \\
\hline $\begin{array}{l}\text { Pesquisa III } \\
\text { Avaliar instituições de formação de docentes } \\
\text { para as séries iniciais do ensino fundamental }\end{array}$ & $\begin{array}{l}\text { - estrutura curricular inadequada para formar o professor alfabetizador } \\
\text { - dificuldade no acesso ao material pedagógico sobre alfabetização } \\
\text { - orientação e estágio em alfabetização de crianças não são prioridades dos cursos }\end{array}$ \\
\hline
\end{tabular}

Fonte: Adaptado de CCEAE (2006).

O comitê aplicou a mesma prova para crianças de escolas privadas, com idade, em média, de 7 anos, e constatou que praticamente todas elas produziram o texto, com riqueza de elementos da linguagem escrita e indicando familiaridade com a cultura letrada. Esse material foi apresentado aos municípios, constituindo uma estratégia de comunicação efetiva, pois indicava claramente uma profunda desigualdade de conhecimentos entre os dois grupos de crianças.

0 comitê tomou o cuidado para que os eventos promovidos por ele não fossem associados a interesses políticos locais diversos, uma vez que 2004 foi ano de eleições municipais. Assim, escolheu divulgar estrategicamente os resultados, de forma a não ranquear os municípios participantes das três pesquisas, bem como promoveu o Seminário Geral após as eleições municipais. Por outro lado, essas estratégias aproveitaram a janela de oportunidade das eleições para que o tema entrasse na agenda municipal e, no início 
de novas gestões municipais, apresentou clima político favorável para efetivamente implementar ações que visassem à promoção da alfabetização escolar (SUMIYA, 2015).

$\mathrm{Na}$ frente de mobilização social, o comitê promoveu dois seminários, sete audiências públicas na capital e no interior e seis plenárias ao longo de 2004. Foram eventos distintos com o intuito de levar o tema para o interior do estado e chamar a atenção para a gravidade do problema, para que fosse incluída nas agendas municipais. Nesses eventos, os educadores tiveram a oportunidade de discutir, a partir dos resultados das pesquisas, o problema da não alfabetização das crianças, com a participação de diversos especialistas.

Apesar das evidências da baixa qualidade do ensino em vários municípios, muitos atores locais não reconheciam o problema central, referindo-se aos programas de educação voltados a jovens e adultos - incluindo os pais dos alunos - como a solução para o problema do analfabetismo. Vale lembrar que essa visão era especialmente reforçada em nível nacional, uma vez que a agenda central de educação básica do governo federal, na gestão de Luiz Inácio Lula da Silva (2003-2010), foi o Programa Brasil Alfabetizado, voltado para a alfabetização de jovens, adultos e idosos (DINIZ; MACHAD0; MOURA, 2014).

Para contra-argumentar essa visão, os membros do comitê utilizavam a seguinte metáfora: "É preciso fechar a torneira e não enxugar o chão. Então nós estamos aqui com o intuito de combater as causas do fracasso da escola pública e não as consequências!" (informação verbal) $^{6}$. Ou seja, fechar a torneira significava atuar prioritariamente nos anos iniciais da escolaridade de forma a não gerar jovens e adultos analfabetos.

Outro ponto central de divergência que surgiu em todas as audiências era sobre o momento ideal para a alfabetização, especialmente quando os educadores consideravam que este seria um processo contínuo e, portanto, não seria possível estabelecer uma idade certa. A visão de que a alfabetização é um processo para toda a vida é difundida em todo o Brasil (OLIVEIRA, 2010) e no Ceará não era diferente. Essa visão, entretanto, era prontamente criticada pelo deputado estadual:

\begin{abstract}
Esse negócio de processo que termina na universidade, eu já fico achando que as pessoas vão achar normal uma pessoa estar na oitava série e não saber ler, porque o processo é um processo que não termina nunca! [...] 0 processo de sofisticação da leitura é interminável, mas a leitura para adquirir conhecimento precisa estar concluída na primeira série, aos 7 anos de idade! (informação verbal) ${ }^{7}$.
\end{abstract}

É interessante observar que esses dois tópicos de maior divergência poderiam criar coalizões advocatórias contrárias às propostas do comitê. No entanto, o que se observou é que o esforço de mobilização trouxe como resultado o convencimento dos atores locais em relação ao problema central que deveriam endereçar, o analfabetismo escolar.

Com a finalização dos trabalhos de mobilização e a apresentação dos resultados das pesquisas pelo comitê, foi elaborada uma proposta de ação organizada em quatro frentes: aprendizagem, políticas de valorização do magistério, gestão municipal e formação

\footnotetext{
6- Rui Aguiar, representante da UNICEF no Ceará, em notas taquigráficas da Audiência Pública de Quixadá, 01.11.2004 (ALECE, 2004b).

7- Ivo Gomes, deputado estadual, notas taquigráficas da Audiência Pública de Crateús, 03.09.2004 (ALECE, 2004a).
} 
docente para a alfabetização de crianças (CCEAE, 2006). Com esse trabalho publicado, o comitê cumpriu o objetivo inicialmente proposto e foi dissolvido no início do ano de 2005, após a realização do seminário final. Nesse evento, surgiram várias demandas pela continuidade das ações, como revelam alguns trechos:

Queria aproveitar o ensejo, deputado Ivo, para estender a nossa gratidão pela responsabilidade que a Assembleia tomou com a sociedade em termos de educação. Isso é inédito na história do Ceará. Sou educadora há 23 anos e nunca vi a Assembleia ou mesmo a Câmara dos Vereadores tomar uma iniciativa como essa, é importantíssimo termos parceiros, não podemos caminhar sozinhos. Muito obrigada por essa empreitada. E queremos dizer que o seu trabalho não termina aqui. Não se pode mexer no formigueiro, deixar as formigas tudo saindo e nós é que vamos ter que botar para dentro, não! Vocês vão ter que estar junto conosco. (informação verbal) ${ }^{8}$.

[...] quero pedir, encarecidamente, que esse comitê se transforme em um instituto e que vá a todos os municípios nos ajudar, no sentido de mudar esse quadro que é preocupante no nosso estado. (informação verbal) ${ }^{9}$.

\section{Esses pedidos eram referendados também pelos especialistas presentes:}

[...] vocês não podem terminar. 0 que nós necessitamos para identificar bem essas necessidades é substituir essa palavra comitê por instituto, ou centro, incorporar o Instituto Cearense para Eliminação do Analfabetismo Escolar como um ponto de referência para as atividades em todo o estado. Isso é possível, isso existe em outros países, e se queremos realmente fazer uma escola primária eficaz nos três primeiros anos, o caminho tem que ser esse: institucionalizar. (informação verbal) ${ }^{10}$.

Nos bastidores, eu notei o comitê com tanta credibilidade que as pessoas, nas suas fragilidades iniciais, nas suas administrações, querendo do comitê um apoio, uma muleta, uma ajuda para o enfrentamento das suas questões diárias lá no município! Então, o comitê, que soube mobilizar, que soube propor, que soube fazer tantas coisas, que não abandone essas pessoas que acreditaram e que não admitem que essa força, essa luz, desapareça. (informação verbal) ${ }^{11}$.

Nesse contexto de demandas, as instituições representativas dos municípios, lideradas pela Associação dos Municípios e Prefeitos do Estado do Ceará (APRECE), e a UNDIME-CE, com o apoio da UNICEF, tomaram a frente das iniciativas. Durante as apresentações de resultados, foram iniciadas as primeiras conversas para que uma ação concreta tivesse início. 0 princípio era de unir forças, de atuar conjuntamente para enfrentarem o mesmo problema. Assim, o presidente da APRECE lançou a ideia de se assinar um pacto entre os municípios:

[...] Já que o comitê vai encerrar os seus trabalhos, entregar esse relatório, tão importante indicador para nós gestores e para a sociedade cearense, que fizemos a propositura de não só a APRECE encampar

8- Liliana Lopes, secretária de educação do município de Maranguape, em notas taquigráficas do Seminário Final, Fortaleza, 17.02.2005.

9- Fabíola Alencar, secretária de educação do município de Crato, notas taquigráficas do Seminário final, dia 17.02.2005.

10- Antonio Gomes Pereira, especialista em educação do Banco Mundial, em notas taquigráficas do Seminário Final, Fortaleza, 17.02.2005.

11- Ada Pimentel, membro do Conselho Estadual de Educação, notas taquigráficas do Seminário Final, 18.02.2005. 
essa luta, de continuar esses trabalhos, mas convocar alguns prefeitos para assinar um pacto pela eliminação do analfabetismo escolar. [...] E, num espaço mínimo, em tempo que for necessário nós conseguirmos tirar essa mancha aqui do nosso estado, porque eu acredito no povo cearense, acredito nos nossos gestores. Não é por causa de uma realidade dessas que vamos desanimar, pois o terreno é propício... eu acho que isso é um trabalho permanente de vigilância, a sociedade civil tem que ser também mobilizada, e tem que ser incluída nesse contexto para que cobrem não só os gestores atuais, porque se é uma coisa permanente tem que se criar uma verdadeira cultura no nosso estado de tirar esses indicadores que tanto nos entristecem e nos envergonham. (informação verbal) ${ }^{12}$.

Essa proposta foi prontamente aceita pelo então presidente da UNDIME-CE, que também alertou para a grande demanda que a iniciativa teria:

Agradeço muito esse apoio da APRECE e, tenho certeza, pelo conhecimento que nós temos dos Secretários Municipais de Educação, que vocês não vão perder o momento de ligar para o seu prefeito ou sua prefeita, para que seja feito um pacto. Nós desejamos que o nosso município esteja inscrito e, com certeza, o Comitê, a APRECE, a Assembleia Legislativa vão ter que limitar as inscrições, pois se não tiver cuidado 184 prefeitos vão aderir. É esse o desejo, pois o Ceará só precisa de uma centelha, acendeu, o resto toca fogo. Então, essa centelha da erradicação do analfabetismo escolar já começou. (informação verbal) ${ }^{13}$.

Portanto, verifica-se que as ações do CCEAE, que ocorreram ao longo de 2004, proporcionaram um processo de aprendizagem nas políticas públicas nos municípios, uma vez que prefeitos, secretários municipais de educação e professores, diante dos resultados das avaliações e das diversas discussões, estavam cientes das fragilidades no desempenho em educação e convencidos das relações causais do sistema de crenças defendido pelo comitê.

0 maior indicativo dessa aprendizagem está no fato de que a liderança do tema do combate ao analfabetismo escolar foi assumida, após a dissolução do comitê, pela APRECE e a UNDIMECE, tendo apoio da UNICEF e da Associação para o Desenvolvimento dos Municípios do Estado do Ceará (APDM-CE) para implementar as mudanças sugeridas pelo comitê. Assim, em 2005, foi lançado o Programa de Alfabetização na Idade Certa (PAIC), com o objetivo de apoiar os municípios cearenses na melhoria da qualidade do ensino, leitura e escrita nos anos iniciais do ensino fundamental, tendo como meta principal promover a autonomia e a competência técnica dos municípios (MARQUES; AGUIAR; CAMPOS, 2009). Segundo o consultor em avaliação da Universidade Federal do Ceará contratado para o programa, a participação das diferentes instituições nessa frente levou a "um ambiente de parceria muito produtivo" (informação verbal) ${ }^{14}$.

Essa primeira versão do PAIC, liderada pelos próprios municípios, pode ser considerada um projeto piloto da futura versão estadual e envolveu 56 municípios. Embora muitos outros desejassem participar, foram impossibilitados pelas limitações orçamentárias (CEARÁ, 2012). 0 trabalho inicial do PAIC foi a realização de duas avaliações externas em leitura e escrita de todos os alunos do segundo ano, com capacitação dos técnicos locais de forma a fortalecer a capacidade municipal. Os resultados indicaram pouca evolução em relação

\footnotetext{
12- Antônio Acioly, presidente da APRECE, notas taquigráficas do Seminário Final, 18.02.2005.

13- Flávio de Araújo Barbosa, presidente da UNDIME-CE, notas taquigráficas do Seminário Final, 17.02.2005.

14- Entrevista concedida por Cláudio Marques, professor da UFC. Entrevista XIII [8 abril, 2015]. Fortaleza. 1 arquivo mp3 (58min).
} 
à avaliação realizada pelo CCEAE e foi constatada a necessidade de se criar um material estruturado para os professores, pois "era complicadíssimo, tinha município que faltava xerox, outro que não recebia o arquivo [...], reproduzir o material saía caro, uma simples ficha de palavras para ligar com o desenho, para vinte alunos, era preciso tirar vinte cópias coloridas", segundo o depoimento da professora da UFC (informação verbal) ${ }^{15}$.

Alguns acadêmicos foram contra a elaboração de um material estruturado para os professores alfabetizadores, pois significaria o retorno a um tecnicismo que não respeitava a autonomia do professor. Porém, segundo a responsável pelo PAIC à época, "seguimos com uma ala da universidade, com pessoas que tinham a cabeça mais aberta, a vivência mais prática" ${ }^{16}$, respaldada pelo fato de várias professoras terem relatado dificuldades em sala de aula. Essa divergência nas ações poderia indicar a formação de uma segunda coalizão que, entretanto, não teve atuação decisiva nos rumos do PAIC.

As principais convicções do projeto piloto do PAIC podem ser sintetizadas em: promover a autonomia municipal; fortalecer a capacidade de gestão; priorizar a alfabetização infantil; e capacitar os professores.

\section{Terceira fase: A formulação da política estadual e a consolidação das crenças}

Nessa última fase, o PAIC tornou-se uma política estadual implementada em todos os 184 municípios cearenses. No contexto político brasileiro, no qual posições ideológicas e político-partidárias costumam definir apoios e tensões, alcançar a totalidade dos municípios revela um apoio maciço à política. Cabe enfatizar que o trabalho realizado nas etapas anteriores, tanto pelo CCEAE quanto o PAIC piloto, foram essenciais para consolidar uma ampla coalização no Ceará em prol da alfabetização na idade certa.

Essa fase teve início quando se abriu uma nova janela de oportunidade, representada pela chegada do ex-prefeito de Sobral, Cid Gomes, ao governo do estado para o mandato de 2007 a 2010.

0 papel central a ser desempenhado pelo governo estadual já tinha sido identificado em momentos anteriores: para o CCEAE, o governo deveria atuar para reduzir as desigualdades em todos os municípios, liderando um pacto societário; e por outro lado, os prefeitos e a UNDIME-CE tinham amplas expectativas com o novo governo, que trazia na sua trajetória a experiência de Sobral e, uma vez no estado, poderia atuar ativamente oferecendo apoio técnico e financeiro aos municípios. Estudos de Sumiya (2015) e Vieira, Plank e Vidal (2019) mostram que a trajetória histórica de atuação colaborativa do governo do estado com seus municípios é um dos fatores explicativos para a compreensão tanto da adesão quanto da implementação bem-sucedida do PAIC em todo o território cearense. Vários trechos de entrevistas com diferentes atores reforçam a expectativa dos municípios, destacando-se alguns exemplos:

Cid Gomes é o primeiro prefeito do interior que é eleito governador no Ceará. Esse fato é importante, deu a ele uma credibilidade para atuar em cooperação com os municípios. (informação verbal) ${ }^{17}$.

\footnotetext{
15- Entrevista concedida por Amália Simonetti, consultora do PAIC, Entrevista XIV [9 abril, 2015]. Fortaleza. 1 arquivo mp3 (83 min).

16- Entrevista concedida por Márcia Campos, ex-coordenadora do PAIC, Entrevista XV [9 abril, 2015]. Fortaleza. 1 arquivo mp3 (52min).

17- Entrevista concedida por Rui Aguiar, representante da UNICEF, Entrevista III [25 março, 2015]. Natal. 1 arquivo mp3 (57 min).
} 
Como ele era prefeito de Sobral, e junto veio a secretária de Sobral, os municípios já sabiam [...] havia muita notícia do que estava acontecendo nos municípios da fase piloto, e também os resultados de Sobral que estavam aparecendo, havia credibilidade do governo... tudo isso favoreceu essa adesão em massa. (informação verbal) ${ }^{18}$.

Para conduzir a política educacional, vários integrantes da prefeitura de Sobral foram convocados pelo novo governador para atuar na Secretaria Estadual de Educação (SEDUC), como o ex-secretário municipal de educação e o deputado estadual que liderou o CCEAE, a coordenadora geral da fase piloto do PAIC, entre outros. 0 estudo de Segatto (2017) também identificou que a difusão de ideias do PAIC ocorreu certamente pela experiência acumulada da equipe técnica municipal de Sobral que passou a fazer parte da equipe estadual.

Se, de um lado, havia uma expectativa dos municípios em relação ao apoio do governo do estado, por outro, o que poderia ocorrer no interior do governo é a formação de uma coalizão contrária à atuação nos anos iniciais da educação, visto que é uma etapa de responsabilidade prioritariamente dos municípios e o estado teria sua própria rede de ensino médio para se preocupar. Mas esse cenário hipotético não aconteceu. Na visão da servidora do estado com 35 anos de experiência, que atuou inicialmente como voluntária do projeto piloto do PAIC e se tornou coordenadora no programa estadual, as crenças preconizadas pelo programa foram ao encontro de seus ideais: "quando conheci o programa acreditei que essa seria a grande solução para a melhoria do ensino médio" (informação verbal) ${ }^{19}$.

Para o então secretário de educação do Ceará, Maurício Maia, que foi integrante da equipe de Sobral, a SEDUC assumiu uma visão de longo prazo tendo clareza da importância de se melhorar a aprendizagem nos anos iniciais para que os alunos chegassem preparados para frequentar as escolas estaduais de ensino médio (informação verbal) ${ }^{20}$.

Portanto, desde o início do governo já havia uma ampla coalizão em prol da alfabetização na idade certa e, condizente com a expectativa já criada em torno de sua atuação, o novo governo elegeu o PAIC como um programa estratégico da área educacional e todos os municípios aderiram a ele. O desenho do PAIC foi elaborado considerando uma visão sistêmica do problema, incluindo as induções necessárias para a coordenação estadual, sendo fruto da aprendizagem na política.

0 aprendizado dos atores protagonistas na formulação do programa consolidou-se na defınição das convicções centrais da política pública e a flexibilidade nas secundárias, processo que será analisado na próxima seção.

\section{Crenças e valores dos atores e o aprendizado das políticas públicas}

Nas convicções centrais profundas, o caso cearense evidencia como um de seus principais valores a defesa da educação básica pública de qualidade como fator essencial para a democracia e uma sociedade mais justa. Princípios de igualdade e busca pela equidade

\footnotetext{
18- Entrevista concedida por Francisco Elicio, secretário executivo da UNDIME-CE, Entrevista XII [8 abril, 2015]. Fortaleza. 1 arquivo mp3 (43 min). 19- Entrevista concedida por Lucidalva Bacelar, coordenadora da Coordenadoria de Cooperação com os Munícipios para Desenvolvimento da Aprendizagem na Idade Certa (COPEM), Entrevista I, [28 agosto, 2014]. 1 arquivo mp3 (65min).

20 - Entrevista concedida por Maurício H. Maia, secretário de educação do Ceará em 2015, Entrevista VI, [7 abril, 2015$].$
} 
são encontrados frequentemente nos argumentos dos entrevistados e no relatório do CCEAE (2006), e defendem o direito de todas as crianças aprenderem, independentemente da sua origem social e classe econômica.

É a partir desse conjunto de convicções centrais profundas que derivam, então, as convicções centrais da política pública e que compõem o nível intermediário do sistema de crenças. Essa segunda camada é composta pelos posicionamentos fundamentais na política pública relativos às estratégias para se atingir os resultados na educação. 0 Quadro 3 sintetiza as convicções do PAIC, contrapondo-as com as convicções presentes na experiência anterior, o que reforça a abordagem das aprendizagens das políticas públicas.

Quadro 3 - As mudanças nas convicções centrais da política pública

\begin{tabular}{|c|c|c|c|}
\hline & Componentes do ACF & Convicções Centrais do PAIC & Convicções Centrais Anteriores \\
\hline \multirow{5}{*}{ 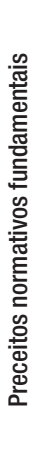 } & \multirow{3}{*}{$\begin{array}{l}\text { 1. Orientação dos atores } \\
\text { quanto aos valores } \\
\text { básicos prioritários }\end{array}$} & Há uma idade certa para ocorrer a alfabetização & $\begin{array}{l}\text { Alfabetização como processo que pode ocorrer até a vida } \\
\text { adulta }\end{array}$ \\
\hline & & Direito de aprendizagem a todas as crianças & Dificuldade de aprendizagem creditada à pobreza \\
\hline & & $\begin{array}{l}\text { Regime de colaboração e parcerias com diversas } \\
\text { instituições }\end{array}$ & $\begin{array}{l}\text { Autonomia dos sistemas municipais e educacionais, a } \\
\text { despeito do regime de colaboração previsto na Constituição } \\
\text { Federal de } 1988\end{array}$ \\
\hline & \multirow{2}{*}{$\begin{array}{l}2 . \quad \text { Identificação dos } \\
\text { grupos cujo bem-estar é } \\
\text { uma preocupação central }\end{array}$} & Crianças em processo de alfabetização & $\begin{array}{l}\text { Não há priorização; alfabetização com foco em jovens e } \\
\text { adultos }\end{array}$ \\
\hline & & $\begin{array}{l}\text { Professores - valorização dos profissionais que atuam } \\
\text { na alfabetização }\end{array}$ & $\begin{array}{l}\text { Valorização salarial dos professores como um todo, devido } \\
\text { ao FUNDEF e FUNDEB }\end{array}$ \\
\hline \multirow{9}{*}{ 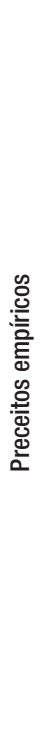 } & \multirow[b]{2}{*}{$\begin{array}{l}\text { 3. Gravidade geral do } \\
\text { problema }\end{array}$} & Resultados muito baixos nas avaliações externas & Não se avaliava \\
\hline & & $\begin{array}{l}\text { Baixa capacidade técnica, humana e financeira dos } \\
\text { municípios }\end{array}$ & Temática não abordada \\
\hline & $\begin{array}{l}\text { 4. Causa básica do } \\
\text { problema }\end{array}$ & $\begin{array}{l}\text { As políticas educacionais não focalizam as crianças no } \\
\text { período de alfabetização }\end{array}$ & $\begin{array}{l}\text { Não havia clareza entre causa e consequência ao focar na } \\
\text { alfabetização dos jovens e adultos }\end{array}$ \\
\hline & \multirow{2}{*}{$\begin{array}{l}\text { 5. Distribuição adequada } \\
\text { de autoridade entre os } \\
\text { níveis de governo }\end{array}$} & Papel coordenador e indutor do Governo Estadual & \multirow{2}{*}{$\begin{array}{l}\text { Ausência de preocupação com a articulação do estado com } \\
\text { os municípios }\end{array}$} \\
\hline & & Respeitar e fortalecer a autonomia dos municípios & \\
\hline & \multirow{3}{*}{$\begin{array}{l}\text { 6. Prioridade atribuída a } \\
\text { diversos instrumentos de } \\
\text { políticas públicas }\end{array}$} & Focalização (alfabetização) & Não havia \\
\hline & & $\begin{array}{l}\text { Avaliação de aprendizagem; uso de metas e indicadores } \\
\text { (gestão pública por resultados) }\end{array}$ & Não se concebia avaliação nesse estágio \\
\hline & & Monitoramento do processo de implementação & Não havia preocupação com o monitoramento \\
\hline & $\begin{array}{l}\text { 7. Participação da } \\
\text { sociedade, especialistas e } \\
\text { políticos eleitos }\end{array}$ & $\begin{array}{l}\text { Ampla participação social: organizações da sociedade } \\
\text { civil, organizações multilaterais, políticos eleitos do } \\
\text { Legislativo e do Executivo, especialistas da academia. }\end{array}$ & Gestão democrática da escola \\
\hline
\end{tabular}

Fonte: Elaboração própria baseada nas categorias de Sabatier e Jenkins-Smith (1993). 
De acordo com Sabatier e Weible (2007), a identificação de dois ou três componentes das convicções centrais das políticas públicas é suficiente para caracterizar uma coalizão. No PAIC, foram constatados sete elementos do total de dez, o que reforça a coesão da coalizão e o compartilhamento das crenças.

Esta pesquisa identificou três valores prioritários básicos, compartilhados pelos atores que pertencem a diferentes organizações. 0 primeiro é a ideia da alfabetização na idade certa, ou seja, a importância de se estabelecer uma idade limite para que a criança aprenda a ler e escrever. A experiência de Sobral levou a um aprendizado na política e essa convicção foi sendo comunicada e disseminada na época do trabalho do comitê e muitos atores passaram a defendê-la. 0 segundo é o direito de aprendizagem a todas as crianças, sem distinção entre escola pública e escola privada e, portanto, sem distinção entre classes sociais. A comunicação institucional do PAIC estadual enfatizou essa crença utilizando o lema: toda criança tem o direito de aprender a ler o mundo. A terceira crença se refere à importância da colaboração e parceria entre diferentes instituições públicas e da sociedade civil, estratégia que esteve sempre presente no caso cearense. Além disso, no desenho do PAIC estadual observou-se o preceito do regime de colaboração à medida que se estabeleceram com clareza as responsabilidades de cada ente federativo - estado e 184 municípios - para trabalhar de modo cooperativo.

No segundo componente dos preceitos normativos fundamentais identifica-se, na política cearense, o grupo das crianças em processo de alfabetização como o público-fim. 0 grupo dos professores representa o público-meio, visto que são profissionais essenciais para se atingir o sucesso na alfabetização das crianças. Uma crença compartilhada foi a necessidade de apoiar o trabalho do professor alfabetizador para que ele possa desenvolver adequadamente sua função, e não culpá-lo pelos baixos resultados. É possível que essa crença seja uma das razões para a ausência de entidades, como os sindicatos, atuando numa coalizão contrária.

Um dos aspectos mais importantes recai nos preceitos empíricos ao analisar a gravidade geral do problema. Essa categoria inclui o processo de aprendizado nas políticas públicas, remontando às suas origens no ano de 2000, em Sobral, quando os investimentos em reforma e ampliação da infraestrutura escolar e no salário dos professores não trouxeram os resultados esperados. A mudança nas convicções centrais da política pública veio na nova gestão municipal, quando houve maior investimento nos aspectos organizacionais da rede, na gestão administrativa e na formação e atuação docente. Os bons resultados confirmaram a relação causal do sistema de crenças e reforçaram a importância de se focar na alfabetização até os 7 anos de idade. Esse processo de reflexão constitui-se num crescente aprendizado que perpassa os membros principais da política sobralense: prefeito, secretários municipais de educação e principais gestores, atores que tiveram papel fundamental nos desdobramentos seguintes. Os baixos resultados no SAEB 2001, bem como a avaliação realizada pelo CCEAE, reforçaram a gravidade do problema em escala estadual.

Outra crença compactuada pelos envolvidos é a baixa capacidade dos municípios de agir diante do problema, ou seja, o principal ente federativo que tem a responsabilidade de ofertar o ensino fundamental inicial não possui condições técnicas, humanas e 
financeiras para atacar os problemas educacionais de forma isolada. Trata-se de uma visão compartilhada por muitos, desde os formuladores da política, da equipe técnica estadual e dos representantes municipalistas.

A categoria seguinte, de acordo com Sabatier e Jenkins-Smith (1993), trata da causa básica do problema. 0 Brasil tem-se debruçado na questão do analfabetismo há algumas décadas, todavia, a atenção maior era destinada a jovens e adultos que não tiveram a oportunidade de frequentar a escola. Assim, havia, até então, uma relativa ausência de políticas voltadas às crianças nos anos iniciais de sua escolaridade. 0 olhar dos atores cearenses ao analfabetismo infantil revela a principal mudança de posicionamento no entendimento da causa básica do problema. Para os autores do modelo, uma crença torna-se crítica para caracterizar uma coalizão quando causas básicas do problema são consensuadas, pois elas influenciam na definição do conjunto de possíveis soluções e, assim, têm efeito sobre aqueles que as financiam.

Assim, quando foi reconhecido o problema do analfabetismo escolar como a principal causa da existência e perpetuação dos analfabetos adultos na sociedade cearense, a escolha de começar pelo começo ${ }^{21}$, em vez de combater as consequências, foi o primeiro passo para se pensar em diferentes estratégias para enfrentar o problema.

Continuando nos componentes dos preceitos empíricos está a distribuição adequada de autoridade entre os níveis de governo. Identificam-se, de um lado, o papel coordenador e indutor desempenhado pelo governo estadual, e de outro, os compromissos assumidos pelos municípios ao aderirem ao programa, na ocasião do lançamento do PAIC. A cooperação entre os entes que possuem autonomia ocorre à medida que há clareza quanto ao papel a ser desempenhado por cada um e os objetivos são acordados por todos.

Na prioridade atribuída a diversos instrumentos de políticas públicas, encontram-se três elementos principais no caso cearense: a focalização, a avaliação de aprendizagem a partir da adoção de metas e indicadores e o acompanhamento e monitoramento dos processos relacionados ao PAIC.

A última categoria trata do grau de participação dos diferentes atores, que é um elemento crítico na formação das coalizões. No caso cearense, diversos atores se uniram em prol de um objetivo comum, o de garantir a alfabetização na idade certa.

Por fim, com relação aos aspectos secundários da política, as entrevistas indicaram que as divergências estão em algumas estratégias adotadas pelo PAIC, manifestadas principalmente pelos acadêmicos e algumas instituições parceiras. 0 principal aspecto questionado, por uma parte da academia, foi a adoção da lógica de gestão pública por resultados, tais como bonificações financeiras e premiações para as escolas, embora também reconheça que essas ações contribuíram para o engajamento dos municípios, professores e famílias. Para outros, como Carneiro (2018), são exatamente essas políticas que explicam o sucesso do Ceará na área educacional. 0 segundo item também questionado pelas universidades foi a entrada da iniciativa privada, no caso as editoras, em alguns municípios, para realizar a formação de professores. Independentemente dos pontos de vista, o fato é que apesar de não haver consenso, essas divergências não afetaram a formação da coalizão. 


\section{Considerações finais}

Este artigo teve como objetivo compreender o processo de formação da coalizão em torno do PAIC a partir de três objetivos específicos: analisar o papel dos principais atores no desenvolvimento da coalizão; caracterizar o sistema de crenças na coalizão; e analisar o processo de aprendizagem na política.

0 estudo mostrou que o compartilhamento do sistema de crenças dos principais atores revelou-se fundamental para a formação da coalizão em torno da alfabetização na idade certa no estado do Ceará.

As convicções centrais profundas, explicitadas na defesa da educação básica pública de qualidade para a democracia e uma sociedade mais justa, com base em princípios de igualdade e na busca pela equidade, foram valores frequentemente encontrados nos argumentos dos atores e no relatório do CCEAE (2006), ao defenderem o direito de todas as crianças aprenderem, independentemente da sua origem social e classe econômica.

As convicções do núcleo central foram expressas por meio do PAIC, que traduz os valores e crenças do núcleo da política pública e representa, portanto, as propostas de ações concretas, desenvolvidas ao longo dos anos, para o enfrentamento do problema da alfabetização escolar. Estudos recentes apontam que o PAIC efetivamente atuou na redução da desigualdade de aprendizagem na educação (KASMIRSKI; GUSMÃO; RIBEIRO, 2017; MAIA, 2020).

A construção desse sistema de crenças não foi simples e linear. Foi observado um intenso processo de aprendizagem nas políticas públicas, desde os primeiros anos em Sobral, pois os péssimos resultados levaram a uma reflexão quanto à validade das relações causais presentes nas políticas públicas. A mudança nas convicções centrais da política pública mostrou-se acertada com os bons resultados obtidos pelos alunos sobralenses. A formação do CCEAE, com articulação de diferentes atores e instituições, foi fundamental para disseminar a crença, em todo o estado, de que "é preciso fechar a torneira e não enxugar o chão", levando ao convencimento dos demais atores municipais sobre as relações causais defendidas e, assim, à revisão de suas convicções centrais. 0 projeto piloto do PAIC pode ser considerado como uma ação concreta derivada das reflexões sobre as mudanças nas convicções centrais da política pública. Além disso, o diagnóstico e os eventos em torno da causa, promovidos pelo CCEAE, fizeram emergir também a fragilidade de grande parte dos municípios cearenses em relação às suas capacidades técnicas e financeiras. A trajetória histórica de cooperação entre os dois entes federativos, somada à aprendizagem da política, levou o governo estadual a assumir o relevante papel de coordenação de um programa que alcance todos os municípios. A visão de que todos os municípios precisariam ser contemplados também reflete um elemento fundamental das convicções centrais profundas: a busca por uma sociedade justa e igualitária.

Nos anos seguintes, no decorrer de sua implementação, constata-se que o desenho do PAIC foi ampliado, passando da preocupação de garantir a alfabetização para a aprendizagem dos alunos. 0 desenvolvimento do programa no âmbito estadual reforça a aprendizagem da política presente no caso cearense: em 2011, o programa incorporou a matemática e ampliou sua atuação até o quinto ano do ensino fundamental. Em 2015, 
passou a ser denominado Programa de Aprendizagem na Idade Certa (Mais PAIC) e abrange os alunos até o nono ano do ensino fundamental, incluindo as competências e habilidades necessárias na área de ciências (CRUZ, 2019). Vieira, Plank e Vidal (2019) elegem três processos estratégicos que criaram condições propícias ao desenvolvimento das políticas educacionais no Ceará: colaboração, mobilização como estratégia de participação e responsabilização, elementos que estão presentes nas convicções centrais do PAIC.

Novas agendas de pesquisa podem avançar na compreensão da forma como as convicções centrais e secundárias são percebidas na ponta do sistema educacional, ou seja, junto aos professores e gestores escolares, estabelecendo um diálogo com estudos sobre a implementação do PAIC e analisando o duplo caminho entre formulação e reformulação de políticas a partir da atuação dos burocratas do nível de rua (BONAMINO et al., 2019; CRUZ, 2019; SEGATTO, 2017).

Outros possíveis aprofundamentos estão nas relações entre a formulação e o monitoramento para analisar processos de realimentação e redesenho de programas de educação (MAIA, 2020; VIEIRA; PLANK; VIDAL, 2019). É possível também desenvolver estudos comparativos para além do PAIC, com outros programas que impactam na sala de aula, combatem a desigualdade escolar e geram valor público.

\section{Referências}

ALECE. Assembleia Legislativa do Ceará. Notas taquigráficas da audiência pública de Cratéus, 3 set. 2004. Ceará: ALECE, 2004a.

ALECE. Assembleia Legislativa do Ceará. Notas taquigráficas da audiência pública de Quixadá, 1 nov. 2004. Ceará: ALECE, 2004b.

ALFERES, Maria Aparecida; MAINARDES, Jefferson. 0 Pacto Nacional pela Alfabetização na Idade Certa em Ação: revisão de literatura. Ensaio, Rio de Janeiro, v. 27, n. 102, p. 47-68, 2019.

ALVES, Maria Teresa Gonzaga; SOARES, José Francisco. Contexto escolar e indicadores educacionais: condições desiguais para a efetivação de uma política de avaliação educacional. Educação e Pesquisa, São Paulo, v. 39, n. 1, p. 177-194, 2013.

BECSKEHÁZY, Ilona. Sobressaltos ou fortuna: as idas e vindas para tentar tirar a educação da idade das cavernas em uma terra desolada. In: DALMON, Danilo Leite; SIQUEIRA, Caetano; BRAGA, Felipe Michel (org.). Políticas educacionais no Brasil: 0 que podemos aprender com casos reais de implementação? São Paulo: SM, 2018. p. 1-26.

BONAMINO, Alicia et al. Arranjo institucional de implementação do PAIC e burocratas de médio escalão. In: LOTTA, Gabriela (org.). Teorias e Análises sobre Implementação de Políticas Públicas no Brasil. Brasília, DF: ENAP, 2019. p. 193-223.

BUENO, Luciano. Políticas públicas do esporte no Brasil: razões para o predomínio do alto rendimento. 2008. Tese (Doutorado em Administração Pública e Governo) - Escola de Administração de Empresas de São Paulo, Fundação Getúlio Vargas, São Paulo, 2008. 
CAPELARI, Mauro; ARAÚJO, Suely; CALMON, Paulo. Advocacy coalition framework: um balanço das pesquisas nacionais. Administração Pública e Gestão Social, Viçosa, v. 7, n. 2, p. 91-99, 2015.

CAPLOW, Theodore. A theory of coalitions in the triad. American Sociological Review, Washington, DC, V. 21, n. 4, p. 489-493, 1956.

CARNEIRO, Diego Rafael Fonseca. Avaliação de políticas de incentivo à educação básica no Ceará: lições para o Brasil. 2018. Tese (Doutorado em Economia) - Universidade Federal do Ceará, Fortaleza, 2018.

CCEAE. Comitê Cearense para a Eliminação do Analfabetismo Escolar. Educação de qualidade começando pelo começo: relatório final do Comitê Cearense para a Eliminação do Analfabetismo Escolar. Fortaleza: Alece, 2006.

CEARÁ. Secretaria de Educação. Regime de colaboração para a garantia do direito à aprendizagem: o Programa Alfabetização na Idade Certa (PAIC) no Ceará. Fortaleza: Seduc, 2012.

CHERTKOFF, Jerome M. The effect of probability of future success on coalition formation. Journal of Experimental Social Psychology, [S. I.], v. 2, p. 265-77, 1966.

COSTA, Leandro; CARNOY, Martin. The effectiveness of an early grades literacy intervention on the cognitive achievement of Brazilian students. Educational Evaluation and Policy Analysis, Thousand Oaks, v. 37, n. 4, p. 1-24, 2015.

CRUZ, Maria do Carmo M. T. Programa Aprendizagem na Idade Certa (Mais Paic): avanços permanentes na busca da equidade. Portal Idea, São Paulo, p. 1-28, 2019. Disponível em: https://portalidea.org.br/ uploads/carminhameirelles_ceara.pdf. Acesso em: 17.jun.2020.

DENZIN, Norman; LINCOLN, Yvonna (org.). Planejamento da pesquisa qualitativa: teorias e abordagens. Porto Alegre: Artmed, 2006.

DINIZ, Gleison M.; MACHADO, Diego; MOURA, Heber José. Políticas públicas de combate ao analfabetismo no Brasil: uma investigação sobre a atuação do Programa Brasil Alfabetizado em municípios do Ceará. Revista de Administração Pública, Rio de Janeiro, v. 48, n. 3, p. 641-666, 2014.

DÖRING, Holger; HELLSTRÖM, Johan. Who gets into government? Coalition formation in European democracies. West European Politics, Abingdon, v. 36, n. 4, p. 683-703, 2013.

FONSECA, Andreia S. A. Programa Alfabetização na Idade Certa - PAIC: reflexos no planejamento e na prática escolar. 2013. Tese (Doutorado em Educação) - Universidade Federal do Ceará, Fortaleza, 2013.

GAMSON, William A. An experimental test of a theory of coalition formation. American Sociological Review, Washington, DC, v. 26, n. 4, p. 565-73, 1961.

HALL, Peter A. Policy paradigms, social learning, and the state: the case of economic policymaking in Britain. Comparative Politics, New York, v. 25, n. 3, p. 275-296, 1993.

HALL, Peter A.; TAYLOR, Rosemary. As três versões do neo-institucionalismo. Lua Nova, São Paulo, n. 58, p. 193-223, 2003. 
IBGE. Instituto Brasileiro de Geografia e Estatística. Tabela 2.29 UF: outras medidas de pobreza, segundo grandes regiões, unidades da federação e municípios das capitais - 2018. Brasília, DF: IBGE, 2019. Disponivel em: https://www.ibge.gov.br/estatisticas/sociais/populacao/9221-sintese-de-indicadoressociais. html?edica0=25875\&t=downloads. Acesso em: 3 fev. 2020.

INEP. Instituto Nacional de Estudos e Pesquisas Educacionais Anísio Teixeira. Vencendo o desafio da aprendizagem nas séries iniciais: a experiência de Sobral-CE. Brasília, DF: INEP, 2005. (Projeto boas práticas na educação).

KASMIRSKI, Paula; GUSMÃO, Joana; RIBEIRO, Vanda. 0 Paic e a equidade nas escolas de ensino fundamental cearenses. Estudos em Avaliação Educacional, São Paulo, v. 8, n. 69. p. 848-873, 2017.

KINGDON, John. Agendas, alternatives, and public policies. 2. ed. New York: Harper Collins College, 1995.

KOHLBACHER, Florian. The use of qualitative content analysis in case study research. Forum Qualitative Social Research, Berlin, v. 7, n. 1, p. 1-30, 2006. Disponível em: https://www.qualitative-research.net/ index.php/fqs/article/view/75/154. Acesso em: 8 out. 2021.

MAIA, Maurício Holanda. Aprendendo a marchar: os desafios da gestão municipal do ensino fundamental e da superação do "analfabetismo escolar". 2006. Tese (Doutorado em Educação) - Universidade Federal do Ceará, Fortaleza, 2006.

MAIA, Maurício Holanda. Firmando os alicerces da igualdade de oportunidades educacionais: 0 Programa Alfabetização na Idade Certa do Ceará. In: MELLO, Janine et al. (org.). Implementação de políticas e atuação de gestores públicos: experiências recentes das políticas de redução das desigualdades. Brasília, DF: IPEA, 2020. p. 157-176.

MARQUES, Cláudio de A.; AGUIAR, Rui; CAMPOS, Márcia. Programa Alfabetização na Idade Certa: concepções, primeiros resultados e perspectivas. Estudos em Avaliação Educacional, São Paulo, v. 20, n. 43, p. 275-291, 2009.

MAYRING, Philipp. Qualitative content analysis. Forum Qualitative Social Research, Berlin, v. 1, n. 2, p. 1-10, 2000. Disponível em: https://www.qualitative-research.net/index.php/fqs/article/ view/1089/2386. Acesso em: 8 out. 2021.

OLIVEIRA, João Batista Araujo. Cartilhas de alfabetização: a redescoberta do código alfabético. Ensaio, Rio de Janeiro, v. 18, n. 69, p. 669-709, 2010.

ROCHA, Carlos Vasconcelos. Ideias e formação de agenda de uma reforma educacional. Ensaio, v. 19, n. 70, p. 191-218, 2011.

SABATIER, Paul A. An advocacy coalition framework of policy change and the role of policy-oriented learning therein. Policy Sciences, Dordrecht, v. 21, n. 2/3, p. 129-168, 1988.

SABATIER, Paul A.; JENKINS-SMITH, Hank C. Policy change and learning: an advocacy coalition approach. Boulder: Westview Press, 1993.

SABATIER, Paul A.; WEIBLE, Cristopher. The advocacy coalition framework: innovations and clarifications. In: SABATIER, Paul A. (ed.). Theories of the policy process. Boulder: Westview Press, 2007. p. 189-222. 
SEGATTO, Catarina lanni. Policy diffusion in subnational governments: State-local relationships in the Brazilian education policy. Regional \& Federal Studies, [S. I.], v. 28, n. 1, p. 79-100, 2017.

SEXTO vídeo institucional 2014 do PAIC. Fortaleza: PAIC, 2015. 1 vídeo (12 min). Publicado pelo canal Secretaria da Educação do Estado do Ceará. Disponível em: https://www.youtube.com/ watch?v=j72j21p2M8s. Acesso em: 8 out. 2021.

SIMIELLI, Lara. Coalizões em educação no Brasil: relação com o governo e influência sobre o Plano de Desenvolvimento da Educação (PDE). Revista de Administração Pública, Rio de Janeiro, v. 47, n. 3, p. 567-586, 2013.

SOBRAL (CE): A contribuição de João Batista Oliveira. Brasília, DF: Instituto Alfa e Beto, 2013. 1 vídeo (5 min). Publicado pelo canal Alfa e Beto. Disponível em: https://www.youtube.com/watch?v=ZWUj64T1BX8. Acesso em: 20 mar. 2016.

SUMIYA, Lilia Asuca. A hora da alfabetização: atores, ideias e instituições na construção do PAIC-CE. 2015. Tese (Doutorado em Administração) - Universidade Federal do Rio Grande do Norte, Natal, 2015.

SUMIYA, Lilia Asuca; ARAÚJO, Maria Arlete de; SANO, Hironobu. A hora da alfabetização no Ceará: o PAIC e suas múltiplas dinâmicas. Arquivos Analíticos de Políticas Educativas, Arizona, v. 25, n. 3, p. 1-30, 2017.

VIEIRA, Sofia L.; PLANK, David N.; VIDAL, Eloisa M. Política educacional no Ceará: processos estratégicos. Educação \& Realidade, Porto Alegre, v. 44, n. 4, 2019.

VINACKE, William Edgar; ARCKOFF, Abe. An experimental study of coalitions in the triad. American Sociological Review, Washington, DC, v. 22, n. 4, p. 406-14, 1957.

YIN, Robert K. Estudo de caso: planejamento e métodos. Porto Alegre: Bookman, 2005.

Recebido em: 14.03.2020

Revisado em: 04.06.2020

Aprovado em: 17.08.2020

Lilia Asuca Sumiya é professora adjunta da UFRN/DAPGS e do Programa de Pós-graduação em Gestão Pública (PPGP). Doutora em administração PPGA/UFRN, mestre em administração pública e governo (FGV EAESP) e bacharel em pedagogia (UNICAMP).

Hironobu Sano é professor associado da UFRN/DAPGS e do Programa de Pós-graduação em Gestão Pública (PPGP) e administração (PPGA). Doutor e mestre em administração pública e governo (FGV EAESP) e graduado em engenharia elétrica (UNICAMP). 